\title{
O LADO HUMANO DO COMPORTAMENTO ANIMAL
}

\author{
THE HUMAN SIDE OF ANIMAL BEHAVIOR
}

\author{
KenNON A. LATTAL \\ WEST VIRGINIA UNIVERSITY, USA
}

\begin{abstract}
RESUMO
Um elemento importante na pesquisa comportamental com animais não humanos é que ela contribui para a compreensão do comportamento humano, o que aqui chamamos de o lado humano do comportamento animal. Este artigo examina as origens da comparação do comportamento humano com o de outros animais, as maneiras como tais comparações são descritas e considerações que surgem de avaliações da validade dessas comparações. A justificativa para tal comparação se originou no reducionismo da fisiologia experimental e no entendimento das similaridades de todas as formas de vida promulgado pela biologia evolucionária darwiniana. Mais recentemente foram adicionadas outras observações, tais como a simplicidade relativa do comportamento animal, afetadas por restrições impostas às comparações resultantes pela ausência do comportamento verbal em animais. A construção de comparações do comportamento humano com o de animais pode ser estruturada com base na distinção de Skinner (1957) entre as formas metafórica e genérica do tato estendido. Tanto a comparação sistemática quanto a ordinária do comportamento humano e animal são congruentes com a abordagem do tato estendido de Skinner. A consideração mais geral ao avaliar comparaçôes do comportamento humano e animal é que seja estabelecida uma base funcional para a similaridade proposta. Análises sistemáticas e evidências convergentes podem contribuir também para a aceitação dessas comparações. $\mathrm{Na}$ análise final, portanto, conclusões sobre o lado humano do comportamento animal não são dedutivamente derivadas e raramente são avaliadas com base em seu valor pragmático e heurístico. Tais conclusões representam uma contribuição valiosa para o entendimento do animal humano e para o desenvolvimento de soluçóes práticas para problemas no comportamento humano aos quais grande parte da psicologia se dedica.
\end{abstract}

Palavras-chave: comportamento animal, comportamento humano, extensão, metáfora, modelo, analogia, simulação, extrapolação, generalização, avaliação

\begin{abstract}
An important element of behavioral research with nonhuman animals is that insights are drawn from it about human behavior, what is called here the human side of animal behavior. This article examines the origins of comparing human behavior to that of other animals, the way in which such comparisons are described, and considerations that arise in evaluating the validity of those comparisons. The rationale for such an approach originated in the reductionism of experimental physiology and the understanding of the commonalities of all life forms promulgated by Darwinian evolutionary biology. Added more recently were such observations as the relative simplicity of animal behavior, tempered by the constraints placed on resulting comparisons by the absence of verbal behavior in animals. The construction of comparisons of human behavior to that of animals may be framed on the basis of Skinner's (1957) distinction between the metaphorical and generic forms of the extended tact. Both ordinary and systematic comparisons of animal and human behavior are congruent with Skinner's extended tact framework. The most general considerations in evaluating comparisons of animal and human behavior is that a functional basis for the claimed similarity be established. Systematic analysis and convergent evidence also may contribute to acceptability of these comparisons. In the final analysis, conclusions about the human side of animal behavior are nondeductively derived and often are assessed based on their heuristic and pragmatic value. Such conclusions represent a valuable contribution to understanding the human animal and in developing practical solutions to problems of human behavior to which much of psychology is dedicated.
\end{abstract}

Key words: animal behavior, human behavior, extension, metaphor, model, analogue, simulation, extrapolation, generalization, evaluation

1 Artigo originalmente publicado em 2001 no The Behavior Analyst, 24 (2), 147-161, que autorizou a publicação da tradução (Copyright by the Association for Behavior Analysis International). Tradução feita por Érik Luca de Mello, Jair Alvércimo M. Mello e Fernando Luca de Mello com a supervisão da professora Josele Abreu-Rodrigues, autorizada pelo autor. 
Os macacos de apego de Harlow, os pombos supersticiosos de Skinner, os macacos executivos de Brady e os cachorros desamparados de Seligman estão entre as imagens mais conhecidas na psicologia (Brady, Porter, Conrad, \& Mason, 1958; Harlow, 1958; Seligman, 1974; Skinner, 1948). Cada um tem sido sugerido para retratar o comportamento humano cotidiano em animais não humanos (daqui em diante descrito como animais), visando revelar o lado humano do comportamento animal. Somente cerca de 7\% das páginas de periódicos publicados pela Associação Americana de Psicologia têm tratado do comportamento animal (N. Miller, 1985). Apesar dessa pequena porcentagem, o impacto de tal trabalho no entendimento do comportamento humano tem sido substancial. Essa pesquisa tem ajudado a construir tanto uma ampla estrutura conceitual para o entendimento e a interpretação do comportamento humano (e.g., Skinner, 1953) quanto áreas específicas de pesquisa de problemas de comportamento humano (e.g., Branch \& Hackenberg, 1998; Domjan, 1987; Epstein, 1986; Keehn, 1986; Maser \& Seligman, 1977; N. Miller, 1975). Tal trabalho, contudo, não existe sem controvérsia. Mesmo que as contribuições tenham sido numerosas, os críticos têm notado deficiências e limitações em basear uma ciência do comportamento humano, em maior ou menor extensão, em conclusões sobre um entendimento de mecanismos comportamentais derivados da pesquisa animal (e.g., Chomsky, 1959; Gardner, 1985; Lowe, 1983; Schwartz, Schuldenfrei, \& Lacey, 1978).

Um aspecto central tanto para responder aos críticos quanto para desenvolver conexões adicionais, amplas e específicas, entre o comportamento animal e humano, é um me- lhor entendimento dos processos ou métodos por meio dos quais os dois são comparados. A despeito do seu papel central, tais processos têm sido freqüentemente assumidos mais do que discutidos, e muito raramente avaliados. Essa revisão, portanto, examina o processo de relacionar o comportamento humano ao de outros animais. Três questões são importantes no processo, e cada uma é considerada separadamente. Como a prática de relacionar o comportamento animal e humano se originou e como ela continua sendo justificada? Como foram estabelecidas as similaridades entre o comportamento animal e humano? E como as similaridades apontadas são avaliadas?

\section{Origens e Justificativas Para Relacionar \\ o Comportamento Animal e Humano}

\section{Origens}

Precedentes históricos freqüentemente estabelecem práticas no início do desenvolvimento de uma disciplina que determinam o desenvolvimento e as práticas posteriores da disciplina. Tal é o caso com a psicologia e o estudo de animais. É, portanto, para esses eventos iniciais que eu me volto primeiro, ao considerar como a psicologia e, mais tarde, a análise do comportamento, desenvolveram a prática de relacionar o comportamento humano e animal.

O uso de observações sistemáticas e da pesquisa com animais para tirar conclusões sobre o comportamento humano começou com a fisiologia do século XIX, quando, por exemplo, o fisiologista francês Bernard observou que "sem [o] estudo comparativo de animais, a medicina prática pode nunca adquirir caráter científico" (1865/1957, p. 126). As relaçóes próximas entre a medicina, a fisiologia e os primeiros anos da psicologia experimental e, particularmente, 
a ênfase em uma abordagem reducionista para estudar o funcionamento humano na fisiologia e na medicina contribuíram para o desenvolvimento da experimentação animal na psicologia. Em 1895, Meyer, um psiquiatra que tinha usado ratos brancos na condição de patologista médico, sugeriu a utilidade do rato como um sujeito para Kline. Kline tornou-se o primeiro psicólogo a usá-los, por volta de 1897, em demonstrações de laboratório para uma aula de psicologia comparativa na Universidade de Clark. Um colega de Kline, Small, construiu o primeiro labirinto para ratos e conduziu os primeiros experimentos em psicologia usando esses animais como sujeitos (Boakes, 1984; ver Small, 1900). No contexto da presente discussão, é irônico que o labirinto da Small tenha sido construído e nomeado com base em um labirinto construído para a diversão de aristocratas no palácio de Hampton Court, na Inglaterra.

Concomitante com os avanços na fisiologia do sistema nervoso que contribuíram para o entendimento do comportamento, a teoria evolucionária de Darwin e o naturalismo do século XIX levaram ao interesse teórico na inteligência e na mente dos animais (Boakes, 1984). Esse interesse, por sua vez, seguiu dois caminhos gerais. Um levou à moderna etologia, com sua ênfase no estudo do comportamento animal em ambientes naturais. $\mathrm{O}$ outro levou à psicologia comparativa que começou com o estudo comparativo da mente e sua evolução, conforme exemplificado pelo trabalho seminal de Thorndike (1898) sobre a inteligência animal. Este último caminho introduziu as tradições de descriçôes objetivas rigorosas e de análises experimentais no estudo psicológico do comportamento animal.

Entre outras coisas, os problemas em fazer comparações comportamentais não trivi- ais através das espécies e a dificuldade mais geral de definir inteligência nos humanos ou nos animais, originou ultimamente uma nova ciência do comportamento humano e animal baseada na aprendizagem. Watson, que usou ratos como sujeitos para sua dissertação e que posteriormente trabalhou extensivamente com psicologia comparativa, afirmou que a aprendizagem era "o grande problema em toda a psicologia humana". A isto ele acrescentou "e qualquer fato que nós possamos coletar sobre os modos como o animal aprende será útil para nós" (1910, p. 351). Ele ainda observou que "o homem emite seus primeiros passos [no aprendizado de uma nova habilidade] exatamente da mesma maneira como o animal" (p. 352) e "não é uma questão difícil mostrar que há uma importância prática para o estudo [da psicologia animal]” (p. 353).

Muito embora a carreira de Watson posteriormente tenha mudado, a nova psicologia da aprendizagem, baseada amplamente no estudo dos animais, ganhou um forte apoio na psicologia americana. $\mathrm{O}$ interesse na aprendizagem como um problema central para a psicologia culminou nas grandes teorias da aprendizagem dos anos 30, propostas por Tolman, Hull, Guthrie e Skinner. Cada um desses teóricos articulou e refinou a noção de que as aprendizagens humana e animal tinham a mesma natureza básica. Tolman (1938), por exemplo, refletiu o otimismo sobre a nova psicologia da aprendizagem quando ele observou que,

Tudo o que é importante na psicologia (exceto, talvez, tópicos como a construção de um superego, isto é, tudo com exceção de tópicos que envolvem sociedade e palavras) pode ser investigado, em essência, por meio da análise experimental e teórica contínua dos determinantes 
do comportamento do rato em um ponto de escolha no labirinto. Isto posto, eu concordo com o professor Hull e também com o professor Thorndike (p. 34).

\section{Justificativas}

Observadores contemporâneos das relações entre o comportamento humano e animal incluem muitos autores de livros recentes de psicologia da aprendizagem. Esses autores justificam o uso de animais, pelos menos em parte, com base na sua importância para o desenvolvimento de princípios comportamentais que são comuns entre muitas espécies. A relevância direta da experimentação animal para o comportamento humano é tanto implícita ou explícita em muitos desses livros, repetindo a observação de Skinner (1953) de que "Nós estudamos o comportamento dos animais porque é mais simples... As condições podem ser melhor controladas" (p. 38; cf. Catania, 1992; Lieberman, 1990; Mazur, 1986; Schwartz, 1989). “O mais simples" é raramente definido com precisão. Entre seus significados implícitos encontramse: (1) variáveis definidas mais facilmente ou em menor número estão envolvidas no controle do comportamento animal em comparação ao comportamento humano multiplamente determinado, (2) variáveis são mais facilmente controladas no estudo do comportamento animal em oposição ao do comportamento humano, ou (3) os processos envolvidos no comportamento animal são de alguma maneira mais básicos.

Também são dadas outras razões para o estudo dos animais. Domjan e Burkhard (1986) acrescentaram que os fatores genéticos podem ser controlados em estudos de aprendizagem com animais (embora, na prática, eles não sejam freqüentemente considerados). $\mathrm{Ou}$ tra justificativa apresentada algumas vezes é que uma amplitude maior de problemas e variáveis pode ser investigada com animais do que com humanos devido ao código de ética diferente para experimentos com animais em oposição àqueles com sujeitos humanos (Domjan \& Burkhard, 1986). Outros têm sugerido que o uso de animais elimina os efeitos de expectativa por parte do sujeito (Mazur, 1986; Zajonc, 1969), uma observação que tem relação com a ausência de linguagem nos animais.

Essa ausência está no centro de um grande corpo de objeções às tentativas de relacionar o comportamento animal ao comportamento humano. Alguns psicólogos reagiram positivamente à ausência de linguagem. Zajonc (1969), por exemplo, sugeriu que essa ausência forçou o uso de medidas não verbais do comportamento. A norma entre muitos outros psicólogos, contudo, varia entre a advertência justificada e a cautela ao relacionar o comportamento de animais não verbais àqueles de humanos verbais:

Por meio de suas respostas de linguagem o indivíduo se tornou uma parte integrante de um sistema de condições que estende seu ambiente virtualmente sem limite em termos de espaço e tempo. Um animal, por outro lado, pode reagir somente às condiçôes imediatas do ambiente durante sua vida e somente dentro dos limites espaciais de seus próprios órgãos do sentido. (Weiss, 1929, pp. 169-170)

Sempre se paga um preço pela conveniência de uma abordagem dada a um problema. O preço a ser pago por tanta experimentação com animais é negligenciar o fato de que os sujeitos humanos são mais brilhantes, são capazes de usar a linguagem - eprovavelmente aprendem diferentemente por causa desses avanços sobre os animais inferiores (Hilgard, 1948, p. 329) 
A indisponibilidade da linguagem como meio cognitivo para os animais estabelece que os modelos de cognição animal vão diferir em muitos aspectos importantes de seus pares humanos. (Roitblat, Beve, \& Terrace, 1984, p. 9)

Tais observações cuidadosas certamente têm fundamento. Por outro lado, há também perigo em enfatizar as diferenças em termos da ausência do comportamento verbal em outros animais à custa de negligenciar ou desconsiderar similaridades válidas. Por exemplo, em trabalho experimental, as diferenças entre o comportamento humano e animal em tarefas básicas, tais como esquemas de reforçamento, têm sido citadas como evidência a favor da descontinuidade entre os animais e os humanos com base, pelo menos em parte, na linguagem (Lowe, 1983). Contudo, em contrapartida, outros autores, tais como Perone, Galizio e Baron (1988), têm sugerido cautela em concluir rapidamente que há descontinuidades entre o comportamento humano e o de outros animais. Eles sugerem, por exemplo, que diferenças nos procedimentos de estudos sobre desempenhos em esquemas de reforçamento de sujeitos humanos e animais podem explicar pelo menos alguns aspectos das diferenças nos desempenhos e, assim, identificar a fonte de algumas das descontinuidades propostas (cf. Joyce \& Chase, 1990; LeFrancois, Chase, \& Joyce, 1988). A observação de Zajonc (1969) de que "a existência de tais descontinuidades é hoje mais uma questão de opinião e conjectura do que um fato estabelecido" (p. 3), permanece relevante em tais discussões. A linguagem certamente acrescenta uma camada de complexidade que requer uma análise contínua, mas, como Sidman (1960, p. 55) notou, diferenças comportamentais entre as espécies são fáceis de se encontrar, mas as similaridades encontradas são freqüentemente mais responsáveis pelo avanço das ciências. É para a análise dessas similaridades que nós agora nos voltamos.

\section{Amplando Conceitos e Princípios}

\section{Relacionar o comportamento humano e} animal envolve estender os conceitos e princípios desenvolvidos em um conjunto de circunstâncias para outro. Como parte de sua análise do comportamento verbal, Skinner (1957) propôs o tato estendido como um processo no qual as práticas verbais - por exemplo, conceitos, princípios ou rótulos - são colocadas sob o controle de novas circunstâncias. Tais tatos estendidos ocorrem quando, após uma resposta verbal ter sido reforçada na presença de um estímulo, "um estímulo novo que possui [uma característica comum com um estímulo original]... evoca uma resposta [verbal similar]" (p. 91). Dois tipos de tato estendido, identificados por Skinner, são genéricos e metafóricos. A extensão genérica é comparável à generalização de estímulo à medida que um estímulo novo é suficientemente similar a um estímulo previamente correlacionado com o reforço e, assim, o estímulo novo passa a controlar uma resposta verbal similar àquela reforçada na presença do estímulo antigo. Ela também se relaciona com a análise de Sidman (1960) da replicação sistemática uma vez que as condições sob as quais um fenômeno é inicialmente observado são estendidas por meio da variação das dimensões da situação original. Extensão metafórica "ocorre por causa do controle exercido pelas propriedades do estímulo, as quais, embora presentes no reforçamento, não entram na contingência considerada pela comunidade verbal" (Skinner, 1957, p. 92). 
Esses dois tipos de extensão podem ser usados para descrever como o comportamento humano e animal têm sido relacionados entre si. Essas extensões, além disso, podem ser identificadas como ordinárias, isto é, baseadas em observação informal e casual, e em descrição conceitualmente relaxada, ou podem ser consideradas sistemáticas. As últimas são apoiadas por uma estrutura conceitual que está fundamentada tipicamente em observações naturalísticas e observações baseadas na experimentação.

\section{Comparaçôes Ordinárias Entre o Com- PORTAMENTO ANimal E Humano}

As comparaçôes entre o comportamento humano e aquele de outros animais em atividades diárias freqüentemente são iniciadas com observaçôes do comportamento animal, que é, então, identificado com processos ou características normalmente associados com seres humanos. Tais comparações ordinárias são antropomórficas ou metafóricas e são os exemplos mais elementares de tentativas de se relacionar o comportamento humano e animal.

\section{Antropomorfismo}

O gato está envergonhado? O pássaro está triste? Declarações antropomórficas são afirmaçõos de similaridades literais assumidas ou isomorfismos entre o comportamento humano e animal. Respostas afirmativas para as duas perguntas acima sugerem similaridades literais: o gato está envergonhado e o pássaro está triste. Essas asserções são baseadas na extensão de características humanas nominais para outras espécies, o processo que Skinner (1957) rotulou de extensão genérica: é assumido que as características comportamentais que controlam o uso desses termos para descrever o comportamento humano também controlam seu uso no caso do comportamento animal. Naturalmente, nem todas as declarações sobre similaridades entre comportamento humano e animal são antropomórficas. Por exemplo, dizer que um cão e um ser humano estão com fome, cansados ou com sono pode significar similaridade literal e não comparação antropomórfica.

Extensões genéricas que são antropomórficas estão sujeitas a várias críticas (ver Kennedy, 1992). Uma das mais antigas é a de Morgan (1894): "De maneira alguma devemos interpretar uma ação como resultado da prática de uma habilidade psíquica superior, se esta pode ser interpretada como o resultado da prática de uma habilidade inferior na escala psicológica” ( $p$. 53). Outra crítica é que muitas das características atribuídas antropomorficamente a animais são ambíguas no comportamento humano do qual elas derivam. Por exemplo, mesmo conceitos psicológicos centrais como ansiedade são definidos de muitas maneiras diferentes na literatura científica, tornando as descrições do comportamento animal baseadas nesses termos ainda mais confusas. Uma pessoa pode definir vergonha como uma "emoção social que parece exigir o conhecimento de como uma pessoa é vista por outra”. Supostamente, esse conhecimento está faltando no gato, o que adiciona um significado excedente ao termo quando aplicado ao comportamento animal. A pergunta mais abrangente nesse caso é se essa definição de vergonha é viável até mesmo para o ser humano. Ela requer autoconhecimento? A vergonha é uma emoção ou um comportamento em um contexto? Como "o conhecimento da aparência de alguém" é determinado?

A despeito da lógica irresistível da regra de Morgan (1894) e de outras críticas ao 
antropomorfismo por cientistas comportamentais, descrições antropomórficas do comportamento animal têm praticantes e defensores contemporâneos (e.g., Griffin, 1984), e também históricos (Romanes, 1882; ver também Baenninger, 1994; Heyes, 1987, e Kennedy, 1992, para comentários adicionais mais aprofundados sobre antropomorfismo na etologia e na psicologia comparativa contemporâneas).

\section{Metáfora}

Considere as duas respostas seguintes: "o cachorro está com ciúmes" e "o cachorro está agindo como se estivesse com ciúmes". No contexto da discussão anterior, a primeira afirmação é antropomórfica se apresentada como sendo literalmente verdadeira. Se, por outro lado, a primeira resposta significa o que a segunda resposta diz, então é uma metáfora. A segunda afirmação é um símile, o qual está incluído aqui em forma de metáfora (ver Skinner, 1957). Davidson (1984) notou que "um símile nos diz o que uma metáfora meramente nos sugere ... O significado figurativo de uma metáfora é o sentido literal de um símile" (p. 253). No sentido funcional de aplicar ou estender um conceito para um novo contexto e para facilitar a descrição, de acordo com sugestôes anteriores de Skinner (1957) e Goodman (1968; citado em Davidson, p. 255), metáfora e símile são considerados juntos aqui. Na versão de metáfora ou de símile da afirmação acima sobre o que é descrito como ciúmes no cachorro, existe controle de uma resposta verbal por propriedades do estímulo que mais tipicamente controlam essa resposta na presença do comportamento humano; conseqüentemente, elas [metáfora e símile] são consistentes com a análise de extensão metafórica de Skinner. Tal extensão tam- bém é sinérgica uma vez que a natureza do conceito original muda quando a metáfora é estendida. Sendo assim, quando afirmamos que o cachorro está com ciúmes, a definição de ciúmes, mesmo que seja imprecisa, é modificada para incluir este novo uso. Como Skinner (1957, p. 93) notou também, uma vez reforçada, uma resposta verbal metafórica deixa de ser uma metáfora.

A extensão metafórica pode facilitar a emergência de novos conceitos a partir de conceitos antigos (Catania, 1992; Schon, 1963). Catania observou que "boa parte do vocabulário técnico evoluiu metaforicamente de fontes concretas do dia-a-dia” (p. 273). Zuriff (1985) foi ainda mais longe notando que "muito longe de serem pejorativos, os adjetivos 'metafórico' e 'analógico' estão no núcleo do pensamento científico mais sofisticado" (pp. 221-222). Alguns dos conceitos mais familiares na psicologia são baseados em metáforas, desde a comparação entre o inconsciente e um iceberg feita por Freud, e o fluxo de consciência de James, até a confiança da teoria do processamento de informações na metáfora do computador. Até mesmo o conceito de reforço foi originado de metáfora.

O controle fraco de estímulos da extensão metafórica também faz com que tal extensão seja importante na linguagem do dia-a-dia e na literatura. Ela permite uma economia de expressão a tal ponto que diversas conotações podem ser resumidas em uma única palavra ou frase. Esse resumo de conotações que a metáfora permite na linguagem e na literatura também se manifesta na extensão de conceitos científicos, como citado no parágrafo anterior. Tal extensão metafórica na ciência, entretanto, é uma faca de dois gumes e talvez tenha sido por isso que Skinner (1957) defendeu que a extensão metafórica "é uma das grandes diferenças 
entre ciência e literatura" (p. 99). A própria flexibilidade que permite extensão também permite ambigüidade e significado adicional no vocabulário científico, resultando em definições confusas de termos como ansiedade e ciúme descritos acima (ver também Mandler \& Kessen, 1959).

\section{Comparaçóes Sistemáticas Entre o Compor- tamento Animal e Humano}

Em contraste às comparações antropomórficas e metafóricas casuais do comportamento humano e animal, em muitos casos as relações estabelecidas entre o comportamento de humanos e o de outros animais são baseadas em observações mais sistemáticas e formais, do tipo que ocorrem no contexto da análise experimental. Adicionalmente, tais comparações têm uma base conceitual que mais comumente é a psicologia da aprendizagem (cf. Domjan, 1987). Ao invés do objetivo de simples descrição que caracteriza as comparaçōes antropomórficas e casualmente metafóricas do comportamento humano e animal, o objetivo da comparação sistemática é a previsão, ou mesmo o controle, do comportamento (cf. Epstein, 1986).

Grosch e Neuringer (1981) observaram que relaçôes sistemáticas entre o comportamento humano e animal podem ser estabelecidas por meio de processos de raciocínio tanto extrapolativo quanto analógico. Estes são, respectivamente, outros dois termos para extensão genérica e metafórica (Skinner, 1957; ver também Zuriff, 1985, pp. 220-222), respectivamente. Muito embora na literatura da psicologia experimental, relacionar sistematicamente o comportamento humano e animal seja descrito de formas diferentes, essas descriçōes diferentes refletem comparações feitas por meio do uso de extensão genérica ou metafórica. A Tabela 1 apresenta exemplos de investigações baseadas nesses dois métodos de extensão juntamente com a descrição das comparações usadas ou sugeridas pelo investigador. Propõe-se que todos os tipos nominais de comparação na Tabela 1 sejam categorizados em dois grupos. No primeiro estão as comparações envolvendo extensões metafóricas e inclui analogias, simulaçōes e modelos. No segundo grupo estão aquelas comparações envolvendo extensōes genéricas e inclui as extrapolações e homologias.

\section{Comparações baseadas em extensão metafórica}

Extensões metafóricas envolvem o que pode ser chamado, na linguagem ordinária, de descrições novas de processos comportamentais de animais. No caso da comparação do comportamento humano e animal, tais extensões tipicamente começam com uma observação do comportamento humano que, por sua vez, conduz a uma tentativa de construir aspectos do comportamento no laboratório animal. Como resultado, uma propriedade do estímulo (neste caso, o comportamento do animal) controla um comportamento verbal, normalmente ou tipicamente associado com um comportamento humano, que não se "encaixa na contingência considerada pela comunidade verbal" (Skinner, 1957, p. 92) com respeito ao comportamento dos animais. Assim, um rótulo como autocontrole, tipicamente controlado por aspectos do comportamento humano, vem a ser usado para descrever o comportamento dos animais sob determinadas condições.

Tais construções são descritas diversamente como modelos, analogias ou simulações. $\mathrm{O}$ uso de diferentes termos para descrever essas construçôes levanta a questão importante de se 
Tabela 1

Exemplos de classes de comportamento humano ou conceitos tipicamente associados ao comportamento humano que têm sido estudadas com animais e descrições atribuídas a tais comparaçôes por seus autores ou sugeridas por eles.

\begin{tabular}{|c|c|c|}
\hline Comportamento humano estudado & Descrito como? & Autores \\
\hline Liberdade & Extrapolação & Catania (1983) \\
\hline Autocontrole & Extrapolação & Catania (1983) \\
\hline Comportamento verbal & Extrapolação & Catania (1983) \\
\hline Insight & Simulaçáo & Epstein (1986) \\
\hline Autoconsciência & Simulação & Epstein (1986) \\
\hline Comunicaçáo simbólica & Simulação & Epstein (1986) \\
\hline Uso de ferramentas & Simulação & Epstein (1986) \\
\hline Uso de memorandos & Simulação & Epstein (1986) \\
\hline Alcoolismo & Modelo, homologia & Falk e Tang (1980) \\
\hline Depressão & Extrapolaçáo & Ferster (1966) \\
\hline Autocontrole & Modelo, analogia & Grosch e Neuringer (1981) \\
\hline Amor & Extrapolaçáo & Harlow (1958) \\
\hline Jogo & Analogia & Kendall (1987) \\
\hline Transmissăo cultural & Extrapolação & Lefebvre e Giraldeau (1994) \\
\hline Comunicaçáo de estados privados & Modelo & Lubinski e Thompson (1987) \\
\hline Fobia & Modelo & Mineka (1987) \\
\hline Anorexia & Modelo & Pierce e Epling (1994) \\
\hline Autocontrole & Extrapolação & Rachlin e Green (1972) \\
\hline Depressão & Modelo & Seligman (1974) \\
\hline Superstição & Extrapolação & Skinner (1984) \\
\hline
\end{tabular}

esses termos implicam em um método distinto de comparação do comportamento animal e humano. Analogias e modelos são, ambos, descrições ou representações incompletas do suposto fenômeno sob investigação, mas elas são incompletas de diferentes maneiras. Uma analogia tem um caráter "como se", comparável a um símile. Em contraste, um modelo tenta representar somente alguns dos aspectos - aqueles essenciais - do fenômeno que está sendo representado. Modelos e analogias são considerados como logicamente distintos na construção formal de teorias. Em tais construções, a seqüência de desenvolvimento começa com uma metáfora, depois muda para analogias, e finalmente, muda para modelos construídos mais precisa ou formalmente (e.g., Pribram, 1980). As relações entre metáfora, analogia e modelo nas comparações do comportamento humano com aquele de animais, contudo, não são tão precisas. Os termos analogia e modelo, freqüentemente são usados indiscriminadamente.
Grosch e Neuringer (1981), por exemplo, observaram que seu experimento "explorou um modelo animal de autocontrole" e no parágrafo seguinte afirmaram que seu "experimento usou a... abordagem da analogia" (p. 3). Mace (1994) observou que "modelos animais [de desordens comportamentais] têm sido usados por pesquisadores comportamentais com resultados promissores... Por exemplo, desamparo aprendido fornece uma analogia e explicação experimental para a depressão” (pp. 544-545). Falk e Tang (1980) descreveram igualmente como as homologias podem servir como modelos. Epstein (1986) igualou modelos e simulações observando que "Algumas simulaçôes mimetizam os fenômenos de modos relativamente arbitrários. Em um extremo estão os modelos" (p. 132). $\mathrm{O}$ mesmo procedimento que Epstein discutiu com uma simulação da comunicação social, Lubinski e Thompson (1987) identificaram como um modelo daquele processo. (Os itálicos foram adicionados em cada uma das citações). 
O termo modelo tem sido usado para descrever os estudos animais de sintomas associados com a patologia comportamental dos humanos (e.g., Keehn, 1986), talvez por causa das conexões da psicologia clínica com a psiquiatria e da psiquiatria, por sua vez, com a medicina em geral. Na última, a pesquisa animal sobre processos fisiológicos e doenças é geralmente rotulada como um modelo da doença sob estudo. O termo, entretanto, pode ser atraente para descrever as comparações do comportamento humano-animal devido ao status de sua associação com modelos animais de funções fisiológicas e doenças. Modelo também é associado com descrições quantitativas relativamente precisas do comportamento. A precisão das comparações do comportamento humano com o modelo animal, contudo, não é maior do que o que é descrito como uma analogia animal ou uma simulação.

Assim, modelo, analogia e simulação são usados, mais ou menos, de maneira indiscriminada, não havendo razão para afirmar que um é diferente ou mais preciso do que os outros. Ao descrever as comparações do comportamento animal e humano esses termos estabelecem ocasiāo para imprecisão e confusão conceitual (cf. Hineline, 1980). Isso não implica que, em outros contextos, os termos têm o mesmo uso ou significado (cf. Kaplan, 1964/ 1998; Mandler \& Kessen, 1959; Pribram, 1980), só que eles não têm sido usados de maneiras sistematicamente diferentes quando aplicados à comparação do comportamento humano e animal. O uso de diferentes termos é controlado por idiossincrasia e, talvez, por contingências científicas e sociais locais, e não por aspectos sistemáticos da comparação que está sendo feita. $\mathrm{O}$ aspecto comum dos três termos é sua base na extensão metafórica e essa parece ser a descrição mais acurada do método das comparações.

\section{Comparações baseadas na extensão genérica} Extensões genéricas, como vimos, envolvem o controle de uma resposta verbal por estímulos que são similares àqueles associados anteriormente com reforçamento. Quando essas extensões são sistemáticas, elas são denominadas pelos pesquisadores de extrapolação, extensão ou generalização. Ao contrário da extensão metafórica, a extensão genérica começa, na maior parte do tempo, com observações de um processo comportamental em animais, as quais são, então, estendidas ao comportamento humano. Uma observação feita por Ferster (1966) ilustra a abordagem: "Se a maior característica da depressão clínica é uma freqüência reduzida do comportamento sob controle normal do ambiente, para aplicar uma análise experimental do comportamento nós temos que determinar primeiro como os processos comportamentais básicos podem aumentar ou diminuir a freqüência do comportamento" (p. 346). Sendo assim, o termo 'extinção', bem como o processo, desenvolvido em laboratório, se estende ao comportamento humano em condiçôes naturais.

Assim como o que ocorre com os diferentes termos usados para descrever extensões metafóricas sistemáticas, os diferentes termos usados para descrever extensões genéricas não conotam diferentes métodos de se fazer comparações. Conseqüentemente, cada um dos três pode ser considerado como um exemplo de um único método de comparação baseado na extensão genérica. $\mathrm{O}$ processo envolve o estabelecimento de um princípio comportamental, a análise dos componentes de um comportamento humano ocorrendo naturalmente, e finalmente, 
a utilização do princípio comportamental derivado no laboratório para explicar os componentes. Sendo assim, um princípio comportamental é extrapolado, estendido ou generalizado da análise do comportamento animal para aquela de humanos. O comportamento humano, então, é descrito como sendo reestruturado, reconceitualizado ou sintetizado (cf. Catania, 1983), em termos dos princípios básicos. Uma vez que os princípios básicos com frequiência são primeiramente formulados com base na experimentação com animais, uma similaridade entre o comportamento humano e animal é inferida.

\section{Homologias e extensão genérica}

$\mathrm{Na}$ biologia evolutiva, estruturas homólogas são aquelas que apresentam origens filogenéticas similares (e.g., a asa de um pássaro e a pata dianteira de um cavalo) a despeito de terem funções diferentes (e.g., voar e caminhar). Essas estruturas podem ser contrastadas àquelas denominadas de análogas, as quais possuem funçôes similares a despeito de suas origens filogenéticas diferentes (e.g., as asas de uma abelha e as asas de um beija-flor) e são resultados de evolução paralela (Lorenz, 1974). Ao aplicar essas descrições a comparações entre o comportamento humano e o de outros animais, padrôes comportamentais que aparentam ser similares, mas que são controlados por processos comportamentais diferentes, são considerados análogos. Padrōes comportamentais que não parecem necessariamente ser os mesmos, mas que são controlados por processos comportamentais idênticos, são considerados homólogos (cf. Lattal, 1998).

Thorndike (1898) parece ter sido o primeiro psicólogo a aplicar o termo homologia na comparação entre o comportamento animal e humano quando ele colocou como aspecto central de sua monografia sobre inteligência animal que a "associação animal é homóloga à associação da psicologia humana" (p. 108). Mais recentemente, psicólogos e analistas de comportamento também têm descrito homologias comportamentais (e.g., Falk \& Tang, 1980). Preocupado com a possível similaridade entre parabenizar a si mesmo com uma recompensa por completar um trabalho e reforçar as respostas de animais com comida, Malott (1993) observou:

Ganhar uma porção de comida depois de colocála no seu garfo é homólogo ao seu cachorro ganhar uma porção de comida depois de rolar... Ambas são contingências de reforçamento de ação direta. Elas têm a mesma funçãa. ... Mas [recompensar a si próprio por escrever um trabalho] é somente análogo ao seu cachorro ganhar uma porção de comida depois de rolar.... O controle que sua contingência exerce sobre sua redação futura é um análogo, governado por regras, do reforçamento e requer habilidades lingüísticas. A contingência do seu cachorro é reforçamento e não requer linguagem... Essas duas contingências são somente análogos superficiais (não são homólogos fundamentalmente relacionados). (pp. 9-10).

Homologias podem ser reclassificadas como instâncias de extensão genérica. O primeiro exemplo de Mallot (1993) ilustra o ponto. O estímulo comum é "ganhar uma porção de comida após uma ação" e a resposta verbal controlada por ambos seria "reforçamento". As extensões descritas na Tabela 1 como analogias são mais parecidas com extensōes metafóricas do que com a definição estrutural oferecida por Mallot, ilustrando novamente a ambigüidade do excesso de termos usados na descrição das 
relaçôes entre comportamento animal e humano. Essa consideração das homologias completa a revisão de como as relações do comportamento humano e animal têm sido construídas. Nós agora nos voltamos para como tais construções podem ser avaliadas.

\section{Avaliação das Relaçōes Propostas Entre Comportamento Humano e Animal}

Avaliar afirmações de similaridade entre o comportamento humano e aquele de outros animais em princípio não é diferente da avaliação de afirmações sobre outras similaridades e diferenças entre espécies ou de como qualquer estudo de comportamento em laboratório está relacionado ao comportamento em ambientes fora do laboratório. Lorenz (1974) sugeriu que "falsa analogia não existe: uma analogia pode ser mais ou menos detalhada e, conseqüentemente, mais ou menos informativa" (p. 230). Uma observação similar pode ser feita para as extensões metafóricas e genéricas entre comportamento humano e animal descritas acima. A força de relaçõos propostas entre comportamento humano e animal não pode ser baseada em sua falseabilidade e nem no critério impossível das duas serem isomórficas. Outras dimensōes devem ser consideradas quando relações propostas entre comportamento animal e humano são avaliadas.

\section{Estrutura versus função}

Provavelmente, a consideração mais universal entre os analistas do comportamento é se as similaridades propostas entre o comportamento humano e animal são focalizadas na estrutura ou na função. Essa é, em parte, a distinção entre analogias e homologias discutida acima. Muitas comparaçôes do comportamento humano e ani- mal, particularmente as antropomórficas e metafóricas, são feitas com base na similaridade superficial da aparência ou topografia do comportamento. $\mathrm{O}$ uso da estrutura como base para comparação não se limita, no entanto, ao antropomorfismo e à metáfora. Marks (1977), por exemplo, fez a observação ambígua que "para serem úteis, modelos de psicopatologia devem compartilhar uma forte semelhança com suas contrapartidas naturais" (p. 174). Se uma semelhança de topografia ou forma está sendo sugerida, a observação é contrária à posição dos analistas do comportamento de que similaridades estruturais entre comportamento humano e animal não são necessárias e nem suficientes para comparações válidas ou úteis entre ambos. Primeiro, qualquer similaridade na aparência pode ser superficial. Segundo, um critério estrutural impediria a análise de muitos fenômenos comportamentais característicos de humanos com animais. Terceiro, empregar um critério estrutural para tais comparações é se comprometer com o que Bachrach (1965) chamou de erro analógico, um ponto reafirmado de maneira diferente por Mallot (1993, discutido acima). Duas instâncias do comportamento podem parecer similares na topografia ou forma, mas as variáveis controladoras podem ser diferentes. Um cachorro letárgico pode ser criado com facilidade, mas igualar a letargia do cachorro à depressão humana com base em uma aparência similar é cometer um erro de analogia. A depressão psicológica em humanos e animais pode compartilhar algumas características, mas essas características são funcionais ao invés de necessariamente similares em forma. De maneira complementar, comportamentos com aparências diferentes em humanos e animais podem ser controlados por variáveis ou processos comportamentais similares. Por exemplo, a forma da vingança em humanos pode 
envolver planejamento e outras formas de comportamento verbal (e.g., O Conde de Monte Cristo de Dumas). O que nós estudaríamos como vingança em ratos e pombos provavelmente teria uma topografia ou aparência diferente. Ainda assim, as variáveis funcionais de controle, em ambos os casos, poderiam ser as mesmas.

\section{A natureza sistemática da comparação}

De maneira geral, os analistas do comportamento preferem observações sistemáticas sob condições controladas em vez de observações mais informais ou casuais. Na maioria dos casos, observações sistemáticas resultam de experimentos em laboratório onde "as propriedades definidoras [dos fenômenos] e... a amplitude da aplicabilidade pode ser refinada" (Catania, 1983, p. 59). Observações mais criteriosas e úteis das relações entre o comportamento humano e animal, contudo, também provêm de observações naturalísticas sistemáticas do comportamento no contexto evolucionário (e.g., Lorenz, 1974). O papel heurístico de uma observação antropomórfica informal ou de uma metáfora casual, entretanto, não pode ser descartado categoricamente. Essas últimas observações são limitadas em termos do foco e da precisão, mas elas podem servir, subseqüentemente, como uma primeira aproximação a comparações mais sistemáticas entre comportamento animal e humano.

\section{Dimensões quantitativas}

A afirmação de similaridades entre o comportamento humano e animal é freqüentemente fortalecida se o comportamento envolve múltiplas similaridades. Isso não é necessário, entretanto, para estabelecer similaridades entre comportamento animal e humano, mas é útil. Essa abordagem de similaridade múltipla às vezes é descrita como o acúmulo de evidência convergente (e.g., Pierce \& Epling, 1994). W. Miller, Rosellini e Seligman (1977) sugeriram que similaridades nos sintomas, etiologia, cura e prevenção podem resultar em um bom teste de um modelo de depressão animal: "Conforme dois fenômenos convergem em um ou dois dos critérios, os pesquisadores podem, então, testar o modelo procurando por similaridades previstas nos outros critérios" (p. 144). Um exemplo de uma comparação cuidadosamente construída na qual várias similaridades entre comportamento humano e animal foram identificadas e posteriormente confirmadas experimentalmente, é o trabalho de Grosch e Neuringer (1981). Eles demonstraram que as variáveis de controle do autocontrole em pombos eram paralelas a variáveis similares no autocontrole em humanos demonstradas em uma série de experimentos conduzidos por Mischel (e.g., 1974). Do mesmo modo, a questão de pontos de similaridade foi o foco de discussão referente ao valor de uma simulação proposta sobre comunicação entre pombos conduzida por Epstein, Lanza e Skinner (1980) (e.g., Savage-Rumbaugh, 1986).

O que pode ser chamado de níveis de similaridade é uma outra dimensão de uma comparação quantitativa. Considere a anorexia nervosa, a qual já foi discutida em três níveis. Primeiro, é uma falha em comer. Segundo, envolve mudanças fisiológicas que podem ter função causal. Terceiro, a anorexia, pelo menos nos humanos, envolve determinantes ambientais, bem como determinantes fisiológicos. Estudos com animais envolvendo esses diferentes níveis provaram ser diferencialmente úteis no tratamento dessa desordem. Simplesmente criar circunstâncias nas quais um animal deixa de comer (uma abordagem estrutural) não é necessariamente útil 
para esclarecer a anorexia humana, porque a falha em comer no animal, assim como nos humanos, pode ser uma função de muitas variáveis. Identificar a base fisiológica da anorexia em animais (e.g., Mrosovsky \& Sherry, 1980) pode ser mais útil, porém não considera os determinantes ambientais da desordem em humanos. Estudos com animais que focalizam determinantes ambientais em sincronia com variáveis fisiológicas, ou seja, aqueles que envolvem níveis múltiplos, podem ser considerados os mais eficazes no desenvolvimento de programas de tratamento (e.g., Pierce \& Epling, 1994).

\section{Dimensões qualitativas}

Embora uma relação proposta entre o comportamento de humanos e de outros animais possa indicar apenas algumas similaridades específicas (ou até mesmo uma) entre as espécies, ela pode ainda estimular uma análise experimental e conceitual das possíveis similaridades. Tais similaridades qualitativas envolvem considerações heurísticas e pragmáticas, ao invés de lógicas, ao avaliar comparações comportamentais animal-humano. Como Catania (1983) apontou,

O sucesso da [analogia] é... julgado não somente com base nos resultados empíricos mas também na extensão em que o entendimento refinado do fenômeno tem implicações para situações humanas, fora do laboratório, das quais a analogia emergiu. (p. 59)

Esse é o critério de "trabalho útil" do pragmatismo (James, 1955). De maneira semelhante, Zurif (1985) observou que uma extrapolação de um fenômeno para outro pode ser considerada como uma "idéia brilhante e como uma demonstração da fertilidade heurística de [afirmações de similaridades entre dois fenômenos]," mas ele então levantou a seguinte questão,

O que, então, distingue este caso do "caso das folhas de chá” onde a extrapolação é inválida? Em ambos os casos, pode-se supor que o cientista forneceu uma defesa da derivação apontando similaridades supostas específicas entre os [dois ] domínios ... A diferença é que em um dos casos, outros vêem as similaridades, e no último caso, eles não vêem. (p. 221)

A maioria das comparações do comportamento humano-animal, como Zuriff (1985) aponta, "não são dedutivamente derivadas" (p. 221), o que deixa os critérios para a avaliação da relação em aberto. Sidman (1960), colocou da seguinte maneira: "a indução não é um processo lógico, é um processo comportamental... a avaliação de generalização é uma questão de julgamento" (p. 59). Hebb e Thompson (1954) apresentaram um argumento comparável como se segue:

O experimento animal pode clarear um problema humano sem "provar" nada. Ele pode chamar a atenção para facetas do comportamento humano que não tenham sido percebidas; pode apontar pressupostos problemáticos, mas implícitos; pode sugerir um novo princípio de comportamento. (p. 533)

\section{Outras consideraçôes}

Validade de face: A questão da aparência. Considerando que a similaridade estrutural entre o comportamento animal e humano não é condição necessária e nem suficiente para uma comparação entre o comportamento humano e animal, qual é o papel da validade de face? Uma 
similaridade na topografia ou aparência física entre comportamento humano e animal é útil ao fazer essas comparações? A validade de face tem um efeito negativo se uma sugestão de similaridade é feita apenas nessa base, na ausência de similaridades funcionais do tipo previamente descrito. Isso ocorre particularmente por causa do potencial para comparações de validade de face serem usadas em situações aplicadas com humanos a despeito de seu valor científico questionável.

Dada uma base funcional para a comparação, entretanto, similaridades na aparência podem aumentar o impacto da comparação, particularmente quando se descreve o trabalho para não cientistas. A validade de face de um fenômeno provavelmente também contribui muito para que outros "vejam" a similaridade afirmada. $\mathrm{Na}$ verdade, algumas das mais bem sucedidas comparações do comportamento humano e animal inclui, em adição a similaridades funcionais, ao menos similaridades superficiais na aparência (e.g., Harlow, 1958; Seligman, 1974).

Seleção de uma espécie. As duas espécies principais dos laboratórios de psicologia, o rato e o pombo, freqüentemente têm sido usadas na investigação animal do comportamento humano. Isso freqüentemente ocorre por questões de disponibilidade e conveniência. Em outros casos, espécies específicas têm sido especialmente úteis, seja por planejamento ou serendipidade. Mineka (1987), por exemplo, usou macacos para desenvolver um modelo animal de comportamento fóbico porque a forte reação que os macacos apresentam diante de cobras é medida facilmente. Talvez as reaçôes específicas de cães ao choque inevitável, combinadas com as reações emocionais humanas aos cães submetidos a tais procedimentos, levou a uma série bem sucedida de conclusões sobre a depressão humana baseada naquele trabalho (Seligman, 1974). A espécie animal certamente não é uma consideração irrelevante ao serem feitas comparaçôes do comportamento humano-animal, mas também não é essencial.

O uso de espécies também se relaciona à questão da validade de face já discutida, à medida que alguns rótulos, originados do comportamento humano, são mais prováveis de serem aceitos do que outros ao serem aplicados ao comportamento animal. Rótulos relacionados a respostas afetivas ou emocionais dos humanos, tais como amor, medo e depressão têm sido usados freqüentemente, e com grande aceitação, em estudos psicológicos com primatas e caninos. A justaposição de outros rótulos e espécies, tais como a empatia das vacas e a angústia das minhocas, é mais provável de evocar controvérsia e ceticismo quanto a sua utilidade e validade. Miles (1983) apresentou uma análise útil dos efeitos de descrições diferentes usadas em comparações do comportamento humano-animal.

Nomeação do comportamento animal. Os rótulos associados ao comportamento animal no laboratório afetam o entendimento do comportamento humano de outras formas também. A maioria dos resultados experimentais está aberta a muitas estruturas conceituais e interpretações diferentes. Discutir autocontrole em vez de simples conformidade a um modelo quantitativo de comportamento de escolha (Rachlin \& Green, 1972), depressão em vez de transferência de aprendizagem (Seligman, 1974), ou transmissão cultural em vez de aprendizagem por meio da imitação (Lefebvre e Giraldeau, 1994), pode atrair uma audiência mais ampla e facilitar a probabilidade da extensão ser reconhecida. Um dos experimentos mais amplamente citados em psi- 
cologia é o de análise do comportamento supersticioso em pombos feito por Skinner (1948). Kellogg (1949) notou corretamente o potencial para problemas mentalistas e antropomórficos levantados pelo uso do conceito de superstição por Skinner, mas se Skinner não o tivesse descrito dessa maneira, seu trabalho provavelmente não teria alcançado sua visibilidade atual. Além disso, estudos como o de Skinner, que tentam relacionar seus resultados a processos comportamentais humanos interessantes, também estimulam o desenvolvimento conceitual e pesquisas ao sugerir relaçôes entre o comportamento humano e as diferentes áreas de investigação dentro da análise do comportamento. Como já foi citado, o impacto é particularmente convincente quando o rótulo verbal é apoiado por uma análise experimental cuidadosa e completa.

Nomear o comportamento animal em termos de supostas contrapartidas humanas, mesmo quando questionável por algum motivo, pode também ter o efeito positivo de forçar a questão da definição do conceito humano em estudo. Baseado em uma análise conceitual e demonstração brilhantes, Epstein (1986) considerou uma instância de um pombo bicando uma marca no peito, visível somente no espelho, como um exemplo de autoconceito, porque uma forma similar de comportamento tinha sido assim denominada nos humanos por alguns investigadores. Embora o uso do rótulo de autoconceito feito por Epstein possa ser controverso nesse contexto, seu trabalho desafiou aqueles que usam tais rótulos a definir mais precisamente seus conceitos.

As funçôes das pesquisas com animais. Pesquisa básica com animais relacionada ao estudo da aprendizagem e dos substratos fisiológicos do comportamento também contribui para o entendimento do comportamento humano.
Toda pesquisa comportamental com animais, entretanto, não pode, e não deve, ser justificada ou avaliada em termos de relevância imediata e direta para a compreensão do comportamento humano. A pesquisa animal em psicologia e em análise do comportamento tem, no mínimo, um valor similar para o desenvolvimento de teoria e para a compreensão do comportamento animal. $\mathrm{O}$ estudo de animais não pode obviamente, suplantar o estudo dos humanos.

\section{CONCLUSÃO}

Alcançar generalidade estendendo observações através de variáveis, ambientes e espécies é uma função importante da ciência (Sidman, 1960). A prática bem estabelecida na psicologia de estudar o comportamento animal para aprofundar o conhecimento do comportamento humano exemplifica essa função. Solicitações recentes de expansão de tais práticas enfatizam sua relevância contínua tanto para a ciência quanto para a prática da análise do comportamento (e.g., Lattal \& Doepke, 2001; Mace, 1994). Ao longo de uma grande quantidade de processos e problemas comportamentais cruciais, um denominador comum é o método pelo qual o comportamento humano é relacionado ao de outros animais. A despeito da variedade, às vezes confusa, de termos utilizados para descrever esses métodos, os processos exemplificam tatos estendidos, especialmente aqueles que Skinner (1957) descreveu como extensão genérica ou metafórica. A significância de tais extensões é afetada pelos métodos com os quais elas são alcançadas, com uma forte tendência para observaçôes controladas e sistemáticas em vez de observações casuais ou ordinárias, e comparações funcionais em vez de estruturais. Conclusóes a respeito do lado humano do comportamento animal não são de- 
rivadas dedutivamente e freqüentemente são avaliadas com base em seus valores pragmático e heurístico. Essas conclusões são valiosas na compreensão do animal humano e no desenvolvimento de soluções práticas para problemas de comportamento humano aos quais grande parte da psicologia é dedicada.

\section{REFERÊNCIAS}

Bachrach, A. J. (1965). Psychological research: An introduction ( $2^{\mathrm{a}} \mathrm{ed}$.). New York: Random House.

Baenninger, R. (1994). A retreat before the canon of parsimony. Contemporary Psychology, 39, 805-807.

Bernard, C. (1865/1957). An introduction to the study of experimental medicine (H. C. Greene, Trads.). New York: Dover.

Boakes, R. A. (1984). From Darwin to behaviorism. Cambridge, England: Cambridge University Press. Brady, J. V., Porter, R. W., Conrad, D. G., \& Mason, J. W. (1958). Avoidance behavior and the development of gastroduodenal ulcers. Journal of the Experimental Analysis of Behavior, 1, 69-72.

Branch, M. N., \& Hackenberg, T. D. (1998). Humans are animals too: Connecting animal research to human behavior and cognition. In W. O’Donohue (Ed.), Learning and behavior therapy (pp. 15-35). Boston: Allyn and Bacon.

Catania, A. C. (1983). Behavior analysis and behavior synthesis in the extrapolation from animal to human behavior. In G. C. L. Davey (Ed.), Animal models of human behavior (pp. 51-69). London: Wiley.

Catania, A. C. (1992). Learning. Englewood Cliffs, NJ: Prentice Hall.

Chomsky, N. (1959). Verbal behavior by B.F. Skinner. Language, 35, 26-58.

Davidson, D. (1984). Inquiries into truth and interpretation. Oxford, England: Clarendon Press.

Domjan, M. (1987). Animal learning comes of age. American Psychologist, 42, 556-564.
Domjan, M., \& Burkhard, B. (1986). The principles of learning and behavior. Pacific Grove, CA: Books/Cole. Epstein, R. (1986). Simulation research in the analysis of behavior. In A. Poling \& W. Fuqua (Eds.), Research methods in applied behavior analysis (pp. 127-155). New York: Plenum.

Epstein, R., Lanza, R. P., \& Skinner, B. F. (1980). Symbolic communication between two pigeons (Columba livia domestica). Science, 207, 543-555.

Falk, J. L., \& Tang, M. (1980). Schedule induction and overindulgence. Alcoholism: Clinical and Experimental Research, 4, 266-270.

Ferster, C. B. (1966). Animal behavior and mental illness. The Psychological Record, 16, 345-356.

Gardner, H. (1985). The mind's new science. New York: Basic Books.

Goodman, N. (1968). Language of art. Indianapolis, IN: Bobbs Merrill.

Griffin, D. R. (1984). Animal thinking. Cambridge, MA: Harvard.

Gorsch, J., \& Neuringer, A. (1981). Self-control in pigeons under the Mischel paradigm. Journal of the Experimental Analysis of Behavior, 35, 3-21.

Harlow, H. (1958). The nature of love. American Psychologist, 13, 674-685.

Hebb, D. O., \& Thompson, W. R. (1954). The social significance of animal studies. In G. Lindzey (Ed.), Handbook of social psychology (Vol. 1, pp. 532-561). Reading, MA: Addison-Wesley.

Heyes, C. M. (1987). Contrasting approaches to the legitimation of intentional language within comparative psychology. Behaviorism, 15, 41-50.

Hineline, P. N. (1980). The language of behavior analysis: Its community, its functions, and its limitations. Behaviorism, 8, 67-86.

Hilgard, E. R. (1948). Theories of learning. New York: Appleton-Century-Crofts.

James, W. (1955). Pragmatism. Cleveland, OH: Meridian.

Joyce, J. H., \& Chase, P. N. (1990). Effects of response 
variability on the sensitivity of rule-governed behavior. Journal of the Experimental Analysis of Behavior, 54, 251-262.

Kaplan, A. (1998). The conduct of inquiry. New Brunswick, NJ: Transaction. (Trabalho original publicado em 1964).

Keehn, J. D. (1986). Animal models for psychiatry. London: Routledge \& Kegan-Paul.

Kellogg, W. N. (1949). "Superstitious" behavior in animals. Psychological Review, 56, 172-175.

Kendall, S. B. (1987). An animal analogue of gambling. The Psychological Record, 37, 247-256.

Kennedy, J. S. (1992). The new anthropomorphism. Cambridge, England: Cambridge University Press.

Lattal, K. A. (1998). A century of effect: Legacies of E. L. Thorndike's Animal Intelligence monograph. Journal of the Experimental Analysis of Behavior, 70, 325-336.

Lattal, K. A., \& Doepke, K. J. (2001). Correspondence as conditional stimulus control: Insigths from experiments with pigeons. Journal of Applied Behavior Analysis, 34, 127-144.

Lefebvre, L., \& Giraldeau, L. -A. (1994). Cultural transmission in pigeons is affected by the number of tutors and bystanders present. Animal Behavior, 47, 331-337.

LeFrancois, J. R., Chase, P. N., \& Joyce, J. H. (1988). The effects of a variety of instructions on human fixed-interval performance. Journal of the Experimental Analysis of Behavior, 49, 383-393.

Lieberman, D. A. (1990). Learning: Behavior and cognition. Belmont, CA: Wadsworth.

Lorenz, K. (1974). Analogy as a source of knowledge. Science, 185, 229-234.

Lowe, C. F. (1983). Radical behaviorism and human psychology. In G. C. L. Davey (Ed.) Animal models of human behavior (pp. 71-93). London: Wiley.

Lubinski, D., \& Thompson, T. (1987). An animal model of the interpersonal communication of interoceptive (private) states. Journal of the Experimental Analysis of Behavior, 48, 1-15.

Mace, F. C. (1994). Basic research needed for stimulating the development of behavior technologies. Journal of the Experimental Analysis of Behavior, 61, 529-550.

Mallot, R. (1993). Response to response. The $A B A$ Newsletter, 16_(3), 9-10.

Mandler, G. E., \& Kessen, W. (1959). The language of psychology. New York: Wiley.

Marks, I. (1977). Clinical phenomena in search of laboratory models. In J. D. Maser \& M. E. P. Seligman (Eds.), Psychopathology: Experimental models (pp. 174-213). San Francisco: Freeman.

Maser, J. D., \& Seligman, M. E. P. (1977). Psychopathology: Experimental models. San Francisco: Freeman.

Mazur, J. E. (1986). Learning and behavior. Englewood Cliffs, NJ: Prentice Hall.

Miles, T. R. (1983). Responsibility in the cockroach: An exercise in linguistic phenomenology. In G. C. L. Davey (Ed.), Animal models of human behavior (pp. 3-13). London: Wiley.

Miller, N. E. (1985). The value of behavioral research with animals. American Psychologist, 401, 423-490.

Miller, W. R., Rosellini, R. A., \& Seligman, M. E. P. (1977). Learned helplessness and depression. In J. D. Maser \& M. E. P. Seligman (Eds.), Psychopathology: Experimental models (pp. 104-130). San Francisco: Freeman.

Mineka, S. (1987). A primate models of phobic fears. In H. Eysenck \& I. Martin (Eds.), Theoretical foundations of behavior therapy (pp. 81-111). New York: Plenum.

Mischel, W. (1974). Processes in delay of gratification. In L. Berkowitz (Ed.), Advances in experimental social psychology, Vol.7 (pp. 249292). New York: Academic.

Morgan, C. L. (1894). An introduction to comparative psychology. London: Scott. 
Mrosovsky, N., \& Sherry, D. F. (1980). Animal anorexias. Science, 207, 837-841.

Perone, M., Galizio, M., \& Baron, A. (1988). The relevance of animal-based principles in the laboratory study of human operant conditioning. In G. Davey \& C. Cullen (Eds.), Human operant conditioning and behavior modification (pp. 59-85). New York: Wiley.

Pierce, W. D., \& Epling, W. F. (1994). Activity anorexia: An interplay between basic and applied behavior analysis. The Behavior Analyst, 17, 7-23.

Pribram, K. (1980). The role of analogy in transcending limits in the brain sciences. Daedalus, 109, 19-38.

Rachlin, H. L., \& Green, L. (1972). Commitment, choice, and self control. Journal of the Experimental Analysis of Behavior, 17, 15-22.

Roitblat, H. L., Bever, T. G., \& Terrace, H. S. (1982). Animal cognition. Hillsdale, NJ: Erlbaum.

Romanes, G. J. (1882). Animal intelligence. London: Kegan, Paul.

Savage-Rumbaugh, E. S. (1986). Ape language: From conditioned response to symbol. New York: Columbia University Press.

Schon, D. A. (1963). Displacement of concepts. London: Tavistock.

Schwartz, B. (1989). Psychology of learning and behavior. New York: Norton.

Schwartz, B., Schuldenfrei, R., \& Lacey, H. (1978). Operant psychology as factory behavior. Behaviorism, 6, 229-254.

Seligman, M. E. P. (1974). Depression and learned helplessness. In R. J. Friedman \& M. Katz (Eds.), The psychology of depression: Contemporary theory and research (pp. 83-113). San Francisco: Freeman.

Sidman, M. (1960). Tatics of scientific research. New York: Basic Books.

Skinner, B. F. (1948). "Superstition" in the pigeon. Journal of Experimental Psychology, 38, 168-172.

Skinner, B. F. (1953). Science and human behavior. New York: MacMillan.

Skinner, B. F. (1957). Verbal behavior. New York: Appleton-Century-Crofts.

Small, W. S. (1900). An experimental study of the mental processes of the white rat. American Journal of Psychology, 11, 133-164.

Thorndike, E. L. (1898). Animal intelligence: An experimental study of the associative processes in animals. Psychological Review Monograph Supplements, 2(4, Todo No.8).

Tolman, E. C. (1938). The determinants of behavior at a choice point. Psychological Review, 45, 1-41.

Watson, J. B. (1910). The new science of animal behavior. Harper's Monthly Magazine, pp. 346-353.

Weiss, A. P. (1929). A theoretical basis of human behavior. Columbus, $\mathrm{OH}$ : Adams.

Zajonc, R. B. (1969). Introduction. In R. B. Zajonc (Ed.), Animal social psychology (pp. 1-5). New York: Wiley.

Zuriff, G. E. (1985). Behaviorism: A conceptual reconstruction. New York: Columbia University Press. 
PROGRAMAS DE PÓS-GRADUAÇÃO STRICTO SENSU EM ANÁLISE DO

COMPORTAMENTO NO BRASIL

BRAZILIAN GRADUATE PROGRAMS IN BEHAVIOR ANALYSIS

PROGRAMA DE PÓS-GRADUAÇÃO EM CIÊNCIAS DO COMPORTAMENTO

Áreas de concentração:

ANÁLISE DO COMPORTAMENTO

NEUROCIÊNCIAS E COMPORTAMENTO

DEPARTAMENTO DE PROCESSOS PSICOLÓGICOS BÁSICOS

UNIVERSIDADE DE BRASÍLIA

COORDENADORA: ELENICE S. HANNA

Cursos: MESTRADO E DOUTORADO

DOCENTES DA ÁREA DE CONCENTRAÇÃO EM ANÁLISE DO COMPORTAMENTO:

David Alan Eckerman

Elenice Seixas Hanna

Jorge Mendes de Oliveira Castro

Josele de Oliveira Abreu Rodrigues

Laércia Abreu Vasconcelos

Lincoln da Silva Gimenes

Informações adicionais e-mail:ppg.cdc@gmail.com 